\title{
Parents' labour market participation as a predictor of children's health and wellbeing: a comparative study in five Nordic countries
}

\author{
C Reinhardt Pedersen, M Madsen
}

J Epidemiol Community Health 2002;56:861-867

See end of article for authors' affiliations

Correspondence to Dr C Reinhardt Pedersen, National Institute of Public Health, Svanemollevej 25, DK-2100, Copenhagen $\varnothing$, Denmark; crp@dike.dk

Accepted for publication 18 December 2001

\begin{abstract}
Objective: To study the association between parents' labour market participation and children's health and wellbeing.

Design: Parent reported data on health and wellbeing among their children from the survey Health and welfare among children and adolescents in the Nordic countries, 1996. A cross sectional study of random samples of children and their families in five Nordic countries (Denmark, Finland, Iceland, Norway, and Sweden).

Participants: A total of 10317 children aged 2-17 years.

Results: Children in families with no parents employed in the past six months had higher prevalence of recurrent psychosomatic symptoms (odds ratio $1.67,95 \%$ confidence intervals 1.16 to 2.40 ), chronic illness (odds ratio 1.35,95\% confidence intervals 1.00 to 1.84 ), and low wellbeing (odds ratio $1.47,95 \%$ confidence intervals 1.12 to 1.94 ). Social class, family type, parents' immigrant status, gender and age of the child, respondent, and country were included as confounders. When social class, family type and the parents' immigrant status (one or more born in the Nordic country versus both born elsewhere) were introduced into the model, the odds ratios were reduced but were still statistically significant. Health outcomes and parents' labour market participation were associated in all five countries.

Conclusions: Children in families with no parents employed in the past six months had higher prevalence of ill health and low wellbeing in the five Nordic countries despite differences in employment rates and social benefits.
\end{abstract}

S udies on social inequality in health use a range of determinants; a key one is labour market participation. Inequality in children's health, with disproportionately many diseases and symptoms among underprivileged groups, has been shown in all countries investigated: in industrialised countries currently and historically and in less developed countries today. ${ }^{1-4}$

Social inequality in health starts at birth. Children born to women with no marketable skills, with little education, or who are unemployed have lower mean birth weight, with a higher percentage of children outside the optimal birthweight range, higher perinatal mortality rates, and higher early and late neonatal mortality rates. ${ }^{148}$ Among older children, children whose parents were unemployed had increased rates of psychosomatic symptoms, nervous symptoms, admission to hospital, and parasuicide. ${ }^{9-13}$ A survey of children's health upon entering school in Denmark showed worse health outcome among children if their father was unemployed. ${ }^{14}$ Children aged 11-15 years in families with income from social welfare payments have been shown to have more psychosomatic symptoms and lower wellbeing than children in families with parents in paid work. ${ }^{15}$ Nevertheless, studies published in the past decade, including ones in Scotland, Finland, and the Netherlands, have found no such social inequality. ${ }^{16-19}$

Many studies seem to support the assumption that unemployment is considered to cause mental distress. ${ }^{11} 132021$ Unemployment may lead to decreased social status, disruption of roles, loss of self esteem, and increased financial strain. All these changes may affect mental health. ${ }^{22}{ }^{23}$ As children are highly sensitive to their parents' emotional state, unemployment can affect the lives of children. ${ }^{24}{ }^{25}$ Parents' unemployment can be accompanied by other potentially adverse factors as experienced by ethnic minority groups or children living with single parents or in stepfamilies.

The Nordic countries are associated with a special model of welfare policy characterised by a general, solidaristic, and universal nature of social legislation: the state redistribution welfare system. ${ }^{26}$ All Nordic countries have groups marginalised by the labour market. The size varies and so does the support society gives to these groups. The traditional family has gradually changed since 1960: more and more women have entered the labour market, and the post-modern family has both parents in paid work and the children in day care institutions. This post-modern family is seen in all the Nordic countries but especially in Denmark, Finland, and Sweden. In general, the Nordic countries have high employment rates despite variation between countries. The proportions of the population aged 16 to 64 years not in paid work in 1996 were $14 \%$ in Iceland, $20 \%$ in Denmark, $21 \%$ in Norway, $22 \%$ in Sweden, and $26 \%$ in Finland. ${ }^{27}$ Men marginalised by the labour market because of unemployment or anticipatory pension are more likely to remain childless, whereas highly educated women are more likely to remain childless than are women with no marketable skills or little education. ${ }^{28}$ The economic stagnation of recent decades resulting in unemployment hit all the Nordic countries, but in some countries the recession came quickly and hit hard and in others it was a slow process, permitting time for adaptation. Denmark experienced high unemployment for more than 20 years, and especially Finland but also Sweden were hit by recession in the 1990s, with huge rises in unemployment and cuts in social benefits. However, in 1996 the economies in all the Nordic countries were growing.

This study analysed the relation between parents' labour market participation and children's health and wellbeing in five Nordic countries. Did children living in families with no 
parent employed in the past six months differ from other children in health and wellbeing? Is this relation stable enough to be seen in five countries that share the same high level of welfare but differ greatly in the proportions of the population marginalised by the labour market?

\section{METHODS}

\section{Sample population and methods}

This study was based on parent reported data from the survey Health and Welfare among Children and Adolescents in the Nordic countries, 1996, a cross sectional study of random samples of children and their families in five Nordic countries (Denmark, Finland, Iceland, Norway, and Sweden). ${ }^{29} 30$

The project was planned and the handling of the questionnaires was organised at the National Institute of Public Health in Denmark, the Social Insurance Institution in Finland, the Directorate of Health in Iceland, the National Institute of Public Health in Norway, and the Nordic School of Public Health in Sweden.

The study included a random sample of 15255 children. A random sample of about 3000 children aged 2-17 years was drawn from the population registers of the respective national bureau of statistics in each participating country. Children living in institutions were excluded. In Finland only children speaking Finnish as their primary language were included (6\% of children in Finland speak Swedish as their primary language). In Denmark, children living in Greenland and the Faeroe Islands were excluded. Parents born in Greenland or the Faeroe Islands were categorised as being born in Denmark.

Two reminders were sent, the last including a new questionnaire, and 10667 completed questionnaires were obtained. In Finland, 350 questionnaires were lost during preparation for scanning, and the final material consisted of 10317 completed questionnaires, corresponding to a response rate of $67.6 \%$. The response rate in Denmark was $68.6 \%$ $(n=2169)$, Finland $67.8 \%(n=2034)$, Iceland $68.1 \%(n=2048)$, Norway $64.5 \%(n=1936)$, and Sweden $69.0 \%(n=2130)$. The internal non-response rate in the completed questionnaires varied from $1.5 \%$ to $10 \%$.

The questionnaire was sent by mail to the parents or, in a few cases, the guardian of the selected child. The instructions asked the parent who was most familiar with the child's situation to fill in the questionnaire together with the child and the other parent if possible. The questionnaire comprised 60 questions on illness, symptoms, wellbeing, socioeconomic data, activities of the child and activities of the child and parents together, contact with the health care system, and the parents' health and wellbeing. The original Swedish questions were translated into Danish, Finnish, Icelandic, and Norwegian and adapted in a few cases because the structure of the health care systems differs.

\section{Analysis of non-respondents}

Non-respondents were analysed in Denmark and Norway. Respondents and non-respondents were compared by register data. The following variables were included: the age of the child and the parents, the gender of the child, family size and structure, and the parents' native country (dichotomised as at least one parent born in the Nordic country versus none), education and profession. In Denmark, the respondents and non-respondents did not differ according to the gender of the child. The following groups were overrepresented among nonrespondents: children older than 14 years $(p<0.01)$, mothers and fathers younger than 25 years or older than 50 years $(p<0.05)$, parents with little education, unskilled workers or not in paid work $(p<0.001)$, single parent families $(p<0.001)$, families with more than three children below 18 years $(\mathrm{p}<$ $0.001)$, and families with no parent born in Denmark $(\mathrm{p}<$ 0.001 ). The response rate varied from $55 \%$ among single parent families to $71 \%$ among two parent families. The mothers' occupational class influenced the response rate. The response rate among mothers not employed was $58 \%$ versus $84 \%$ among mothers who were not manual workers and of high social class. The response rate in families with at least one parent born in Denmark was 70\% versus 53\% in families with no parent born in Denmark. The non-respondent analysis in Norway obtained comparable results. In Finland and Sweden, modified non-respondent analysis was conducted by comparing respondents with information from national registers on all children aged 2-17 years. In Sweden the items mentioned above did not differ significantly between respondents and the general population. However, the following groups were nonsignificantly underrepresented among respondents: children aged 2-6 years, families with only one child below 18 years, parent less than 40 years, parents born outside the Nordic countries, single parent families, and main bread winner who was skilled or unskilled manual worker. In Finland no significant differences were seen among respondents compared with the general population in regard to age and gender of the children or the geographical distribution. Non-respondents were not analysed in Iceland.

\section{Measurements of health and wellbeing}

This study used three indicators to describe children's health status: recurrent psychosomatic symptoms, chronic illness, and level of wellbeing.

\section{Recurrent psychosomatic symptoms}

Recurrent psychosomatic symptoms were defined as a parent reporting at least one moderate or severe symptom at least every two weeks. The list of symptoms and complains included: stomach pain, headache, back pain, sleep disorders, dizziness, and loss of appetite and "other (please specify)".

\section{Chronic illness}

Chronic illness was defined as a parent reporting at least one moderate or severe chronic illness or disability that had considerably affected the child's daily life during at least three of the past 12 months. The list of chronic illnesses included: diabetes, visual impairment, hearing impairment, speech defect, mental disorder, epilepsy, gastric disorder, asthma, allergies, eczema, physical disability, overweight, and hyperactivity and "other (please specify)".

\section{Level of wellbeing}

The child's self esteem was measured by six indicators: dependent versus independent, passive versus active, lonely versus not lonely, restless versus calm, depressed versus happy, and anxious versus confident. The parents rated each item on a scale from 1 to 7 , the higher values indicating more positive psychological attributes compared with children of the same age. The maximal score was $7 \times 6=42$ points and was dichotomised as the lowest quintile versus the rest. This index was constructed and validated by Lindström as part of a measure of quality of life for children in the Nordic countries. $^{31} 32$

\section{Measuring parents' labour market participation}

The measure for parents' labour market participation was dichotomised: at least one parent in the family employed in the past six months versus no parent employed in the past six months. Parents not employed were a mixed group, especially the women. The group consisted of unemployed people, people on long term sick leave from illness, people awarded an anticipatory pension, people in an educational programme, and housewives. A total of 436 children lived in families with no parents employed; 244 of these (56\%) lived in single parent families, mostly with their mother. Single parents not employed were assigned as follows: $43 \%$ unemployed, $37 \%$ in an educational programme, $9 \%$ housewives, $10 \%$ long term absence because of illness, $1 \%$ anticipatory pension. Among 


\begin{tabular}{|c|c|c|c|c|c|c|}
\hline & Denmark & Finland & Iceland & Norway & Sweden & Total \\
\hline \multicolumn{7}{|l|}{ Outcome measures (\%) } \\
\hline Recurrent psychosomatic symptoms & 7.6 & 10.1 & 8.6 & 9.3 & 7.2 & 8.5 \\
\hline Chronic illness & 13.5 & 17.5 & 20.1 & 15.4 & 12.9 & 15.7 \\
\hline Low wellbeing & 18.4 & 28.0 & 35.7 & 20.8 & 21.8 & 24.9 \\
\hline \multicolumn{7}{|l|}{ Labour market participation } \\
\hline No parent employed (\%) & 5.5 & 3.6 & 2.5 & 3.5 & 6.5 & 4.3 \\
\hline \multicolumn{7}{|l|}{ Confounding variable } \\
\hline \multicolumn{7}{|l|}{ Social class } \\
\hline High & 31.9 & 34.6 & 43.2 & 34.7 & 32.6 & 35.4 \\
\hline Middle & 39.4 & 33.5 & 31.0 & 45.3 & 36.6 & 37.1 \\
\hline Low & 28.7 & 31.9 & 25.8 & 20.0 & 30.8 & 27.5 \\
\hline \multicolumn{7}{|l|}{ Family type (\%) } \\
\hline Traditional family & 79.9 & 81.7 & 81.5 & 80.1 & 81.1 & 80.9 \\
\hline Single parent family & 12.2 & 14.1 & 11.1 & 13.0 & 12.2 & 12.5 \\
\hline Stepfamily & 7.9 & 4.1 & 7.3 & 7.0 & 6.7 & 6.6 \\
\hline \multicolumn{7}{|l|}{ Parents' immigrant status (\%) } \\
\hline Children of immigrants & 4.2 & 1.2 & Not asked & 2.4 & 9.7 & 3.6 \\
\hline Children of non-immigrants & 95.8 & 98.8 & 100 & 97.6 & 90.3 & 96.4 \\
\hline \multicolumn{7}{|l|}{ Gender (\%) } \\
\hline Boys & 49.7 & 52.0 & 50.2 & 52.2 & 52.9 & 51.4 \\
\hline Girls & 50.3 & 48.0 & 49.8 & 47.8 & 47.1 & 48.6 \\
\hline \multicolumn{7}{|l|}{ Age (y) (\%) } \\
\hline $2-6$ & 33.7 & 29.6 & 34.9 & 32.8 & 33.3 & 32.9 \\
\hline $7-12$ & 36.1 & 38.5 & 37.9 & 37.1 & 37.7 & 37.5 \\
\hline 13-17 & 30.1 & 31.9 & 27.2 & 30.1 & 29.0 & 29.7 \\
\hline \multicolumn{7}{|l|}{ Respondent (\%) } \\
\hline Mother & 80.3 & 84.9 & 83.5 & 76.9 & 80.6 & 81.3 \\
\hline Father & 12.6 & 9.2 & 8.1 & 17.0 & 13.3 & 12.0 \\
\hline Mother and father or other & 7.1 & 5.9 & 8.4 & 6.0 & 6.1 & 6.7 \\
\hline
\end{tabular}

two parent families ( 192 children, 44\%), the largest group was both parents unemployed $(40 \%)$. Both parents were in an educational programme in $16 \%$ of these families. The remaining $44 \%$ were assigned different combinations.

\section{Potential confounding variables \\ Social class}

As an indicator on socioeconomic status parents' social class was used. The Swedish socioeconomic classification (SEI) was used to classify parents' currently or former occupation. The classification is based on trade union affiliation and the educational requirements for different occupations and is considered to be applicable to all Nordic countries. ${ }^{33}$ For each child in the study social class was defined as the highest social class in the family. The children were grouped into three groups: (1) low social class: skilled and unskilled manual worker and parents in an educational programme, (2) middle social class: assistant non-manual and intermediate nonmanual, (3) high social class: highest non-manual and self employed.

\section{Family type}

The children were grouped into three groups: traditional family-the child lives with two biological or adoptive parents; a single parent family, the child living with one biological or adoptive parent; and a stepfamily - the child lives with one biological or adoptive parent and a step-parent.

\section{The parents' native country}

This variable was dichotomised: one or more parent born in the Nordic country versus both or a single parent born elsewhere. Children with no parents born in the country are named children of immigrants here. The Icelandic questionnaire did not include this item in their study, because very few people living in Iceland were born outside Iceland. Some parents not born in the country were born in another Nordic country. This was the case for $47(23 \%)$ of the children of immigrants in Sweden, $12(13 \%)$ in Denmark, $5(11 \%)$ in Norway, and $0(0 \%)$ in Finland, the overall percentage being $18 \%$. For most of the families in which both parents were born outside the Nordic countries, both parents were born in the same country or at least in the same region.

\section{Gender and age}

Gender of the child. Age of the child (in three age groups, 2-6 years, $7-12$ years, $13-17$ years).

\section{Respondent}

The parent who was best familiar with the child's situation was instructed to fill in the questionnaire. Respondent in three groups (1) mother (2) father (3) mother and father or other

\section{Country}

Denmark, Finland, Iceland, Norway, and Sweden.

\section{Statistical analysis}

The statistical analysis was performed as logistic regression separate for each of the three dependent variables: recurrent psychosomatic symptoms, chronic illness, and low wellbeing. The measure for parents' labour market participation and the potential confounding variables were included in the statistical model simultaneously. The $\mathrm{p}$ values indicate the effect of excluding this variable from the model. All tests for interaction effect are conducted by introducing one interaction term in the model. The Hosmer-Lemeshow goodness of fit test was conducted for all models analysed with logistic regression.

\section{RESULTS}

Table 1 shows key information about the children and their parents. The prevalence of the three health indicators are shown: $8.5 \%$ of the children had one or more recurrent psychosomatic symptom varying from $7,2 \%$ in Sweden to $10.1 \%$ in Finland. Some $15.7 \%$ had one or more chronic illness, 
Table 2 Adjusted odds ratios (95\% confidence intervals) and $p$ values for recurrent psychosomatic symptoms, chronic illness, and low wellbeing

\begin{tabular}{|c|c|c|c|}
\hline & $\begin{array}{l}\text { Recurrent psychosomatic } \\
\text { symptoms }\end{array}$ & Chronic illness & Low wellbeing \\
\hline Parents' labour market participation & $p<0.01$ & $p<0.05$ & $p<0.01$ \\
\hline One or two parents employed & 1.00 & 1.00 & 1.00 \\
\hline No parent employed in the past 6 months & $1.67(1.16$ to 2.40$)$ & 1.35 (1.00 to 1.84 ) & 1.47 (1.12 to 1.94$)$ \\
\hline Social class & $p<0.001$ & $p<0.01$ & NS \\
\hline High social class & 1.00 & 1.00 & 1.00 \\
\hline Middle social class & 1.27 (1.05 to 1.53$)$ & 1.08 (0.93 to 1.24 ) & $1.00(0.89$ to 1.13$)$ \\
\hline Low social class & 1.50 (1.23 to 1.83$)$ & 1.33 (1.14 to 1.55$)$ & $1.12(0.98$ to 1.27$)$ \\
\hline Family type & $p<0.001$ & $p<0.001$ & $p<0.001$ \\
\hline Traditional family & 1.00 & 1.00 & 1.00 \\
\hline Single-parent family & $1.20(0.95$ to 1.51$)$ & 1.44 (1.21 to 1.73 ) & $1.10(0.94$ to 1.29$)$ \\
\hline Stepfamily & 1.73 (1.34 to 2.24 ) & 1.59 (1.28 to 1.97$)$ & 1.60 (1.33 to 1.92$)$ \\
\hline Parents' immigrant status & $p<0.01$ & NS & $p<0.01$ \\
\hline Children of non-immigrants & 1.00 & 1.00 & 1.00 \\
\hline Children of immigrants & 1.76 (1.20 to 2.59$)$ & $1.13(0.80$ to 1.61$)$ & 1.65 (1.22 to 2.21$)$ \\
\hline Gender & $p<0.001$ & NS & $p<0.001$ \\
\hline Boys & 1.00 & 1.00 & 1.00 \\
\hline Girls & 1.71 (1.46 to 1.99 ) & 0.95 (0.84 to 1.06$)$ & $0.77(0.70$ to 0.85$)$ \\
\hline Age (y) & $p<0.001$ & $p<0.01$ & $p<0.001$ \\
\hline $2-6$ & 1.00 & 1.00 & 1.00 \\
\hline $7-12$ & 1.54 (1.25 to 1.89 ) & 0.92 (0.79 to 1.06$)$ & $1.25(1.11$ to 1.41$)$ \\
\hline $13-17$ & $2.59(2.11$ to 3.18$)$ & 1.18 (1.01 to 1.37$)$ & $1.29(1.14$ to 1.46$)$ \\
\hline Respondent & $p<0.05$ & NS & $p<0.001$ \\
\hline Mother & 1.00 & 1.00 & 1.00 \\
\hline Father & 0.72 (0.55 to 0.94$)$ & $0.80(0.66$ to 0.98$)$ & 1.27 (1.09 to 1.47$)$ \\
\hline Mother and father or others & 1.14 (0.84 to 1.54$)$ & $1.06(0.82$ to 1.36$)$ & 0.73 (0.58 to 0.92$)$ \\
\hline Country & $p<0.001$ & $p<0.001$ & $p<0.001$ \\
\hline Denmark & 1.00 & 1.00 & 1.00 \\
\hline Finland & $1.61(1.27$ to 2.05$)$ & 1.37 (1.14 to 1.66 ) & 1.82 (1.55 to 2.14$)$ \\
\hline Iceland & 1.30 (1.02 to 1.65$)$ & 1.69 (1.41 to 2.02$)$ & 2.61 (2.25 to 3.04$)$ \\
\hline Norway & 1.37 (1.07 to 1.76$)$ & 1.21 (1.00 to 1.47 ) & $1.14(0.96$ to 1.35$)$ \\
\hline Sweden & 1.01 (0.79 to 1.29 ) & $0.92(0.76$ to 1.11$)$ & $1.20(1.02$ to 1.41$)$ \\
\hline
\end{tabular}

The measure for parents' labour market participation and the potential confounding variables (social class, family type, parents' immigrant status, gender, and age of the child, respondent and country) were included in the statistical model simultaneously.

varying from $12.9 \%$ in Sweden to $20.1 \%$ in Iceland. The prevalence of children with low wellbeing varied from $18.4 \%$ in Denmark to $35.7 \%$ in Iceland. A total of $4.3 \%$ of the children lived in families with no parent employed in the past six months: $2.5 \%$ in Iceland, $3.5 \%$ in Norway, $3.6 \%$ in Finland, $5.5 \%$ in Denmark, and $6.5 \%$ in Sweden. The table also shows the distribution of participating children according to the confounders.

Table 2 shows the results of logistic regression with parents' labour market participation as the independent variable. The dependent variables were recurrent psychosomatic symptoms, chronic illness, and low wellbeing, respectively. The confounders included in the model were social class, family type, parents' immigrant status, gender and age of the child, respondent, and country. The degrees of freedom are reduced because Iceland did not include parents' native countries in the questionnaire.

Children with no parent employed in the past six months had higher prevalence of recurrent psychosomatic symptoms, chronic illness, and low wellbeing than did children in families with at least one parent employed. Introducing interaction terms in the model showed no significant interaction between country and parents' labour market participation for any of the three health indicators $(p=0.49, p=0.65, p=0.53$, respectively): the influence on children's health and wellbeing did not differ significantly between the countries. All confounding variables were tested for interaction with parents' labour market participation. No significant interaction were seen ( $\mathrm{p}$ values not shown).
Each confounding variables included in the model were significant associated with two or three of the three health indicators investigated. Children from low social class had higher prevalence of recurrent psychosomatic symptoms and chronic illness compared with children from high social class. Children from middle social class had higher prevalence of recurrent psychosomatic symptoms compared with children in high social class.

Children in stepfamilies had higher prevalence of recurrent psychosomatic symptoms, chronic illness, and low wellbeing than did children in traditional families. Children in single parent families showed higher prevalence of recurrent psychosomatic symptoms and chronic illness, but the differences in wellbeing were not significant. Children of immigrants showed higher prevalence of recurrent psychosomatic symptoms and low wellbeing. The prevalence of recurrent psychosomatic symptoms was higher among girls than boys and higher among children older than 6 years than among younger children. Correspondingly, low wellbeing was more prevalent among boys than girls, and more children among the two oldest age groups had low wellbeing than did children in the youngest age group. Chronic illness was more prevalent among the oldest age group compared with the youngest. Genders groups did not differ in chronic illness. The gender of the proxy respondent was associated with responses to health indicators. Fathers reported fewer chronic illnesses and fewer recurrent psychosomatic symptoms than did mothers. In contrast, fathers more frequently reported low wellbeing among children than did mothers. The prevalence of recurrent 
Table 3 Adjusted odds ratios (95\% confidence intervals) for recurrent psychosomatic symptoms, chronic illness, and low wellbeing among children from families with no parents employed in the past six months compared with families with at least one parent employed. Stepwise inclusion of the three confounding variables: social class, family type, and parents' native country

Recurrent

psychosomatic symptoms Chronic illness Low wellbeing

Parents' labour market participation 2.24 (1.68 to 2.97$) \quad 2.02$ (1.59 to 2.55$) \quad 1.66(1.32$ to 2.08$)$ Parents' labour market participation and socioeconomic status 1.85 (1.33 to 2.57$) \quad 1.62(1.23$ to 2.12$) \quad 1.58(1.23$ to 2.02$)$ Parents' labour market participation, socioeconomic status, and family type $1.80(1.27$ to 2.55$) \quad 1.37(1.02$ to 1.83$) \quad 1.57(1.20$ to 2.05$)$ Parents' labour market participation, socioeconomic status, family type, and native country of the parents

$1.66(1.16$ to 2.38$) \quad 1.35$ (1.00 to 1.84$) \quad 1.47(1.12$ to 1.94$)$

The following confounders were included in all models analysed: the gender and age of the child, respondent and country

psychosomatic symptoms and chronic illness were higher in Finland, Iceland, and Norway than in Denmark and Sweden. The proportion of children with low wellbeing was lowest in Denmark, higher in Finland and Sweden, and highest in Iceland. The proportion of children with low wellbeing in Norway did not differ significantly from the proportion in Denmark.

Social class, family type, and parents' immigrant status were all associated with the health and wellbeing of children as assessed above. Labour market participation was not distributed equally among the three social classes, among different family types, or among immigrants and nonimmigrants in our data. Figures not shown. Table 3 illustrates the influence of social class, family type, and parents' immigrant status on the three indicators of health and wellbeing among children. The odds ratios for recurrent psychosomatic symptoms, chronic illness, and low wellbeing are shown with parents' labour market participation as the independent variable when neither social class or family type nor parents' immigrant status are included in the model and when these variables are included. The odds ratios declined modestly but are still statistically significant.

\section{DISCUSSION}

Children in families with no parent employed in the past six months had increased prevalence of recurrent psychosomatic symptoms, chronic illness, and low wellbeing. When social class, family type, and the parents' immigrant status were introduced in the model, the odds ratios were only modestly reduced and still statistically significant. The Nordic countries did not differ in the correlation between parents' labour market participation and the prevalence of recurrent psychosomatic symptoms, chronic illness, and low wellbeing among children despite the differences among the Nordic countries in the proportion of the population employed and differences in the prevalence of the three health indicators between the countries. The associations between the indicators of health and wellbeing and parents' labour market participation were similar among boys and girls and in the three age groups.

The confounders: social class, family type, and parents' immigrant status illustrates the accumulation of risk factors within families. Children from low social class had higher prevalence of recurrent psychosomatic symptoms and chronic illness compared with children from high social class, children from middle social class had higher prevalence of recurrent psychosomatic symptoms compared with children in high social class. Family type was associated with the investigated indicators of health and wellbeing among children. For all three indicators, children in stepfamilies had worse outcome than did children in traditional families. Children in single parent families had higher prevalence rates of recurrent psychosomatic symptoms and chronic illness, but the proportion with low wellbeing did not differ from that in traditional families. Children of immigrants had higher prevalence of recurrent psychosomatic symptoms and low wellbeing compared with children of non-immigrants.

The main results are in accordance with a previously survey of children's health upon entering school in Denmark, in which the prevalence of psychosomatic symptoms and unhappiness among children was higher when the father was unemployed. The same study reported lower wellbeing among children of immigrants compared with children with a parent born in Denmark. ${ }^{14}$ A study on the health and lifestyles among children aged 11-15 years concludes that children aged 11-15 years in families whose income is derived from social welfare payments have more psychosomatic symptoms, worse wellbeing, increased risk behaviour, and increased use of medicine than do children in families with a parent in paid work. ${ }^{15} \mathrm{~A}$ study in Sweden has also shown increased prevalence rates of symptoms among children of immigrants. ${ }^{34}$ Research consistently reports higher rates of problems for children in single parent and stepparent families. Divorce and repartnering are parts of a chain of events that involve children in a host of other changes-changes in financial circumstances, neighbourhoods, schools, extended families, relations with peers, the presence of step siblings and half siblings, and family discord. ${ }^{35-38}$

The prevalence of health indicators varied according to the gender of the respondent. Other studies have shown the same pattern, with fathers reporting less chronic illness and fewer accidents within the past year than did mothers but no differences in reports on visits to the physician or admission to hospital. ${ }^{39}$

Only $4.3 \%$ of children were in families with no parents employed. Although the differences in health and wellbeing between children grouped according to parents' labour market participation are statistically significant, the odds ratios are less than 2 for all three indicators of health and wellbeing. Most children with recurrent psychosomatic symptoms, chronic illness, and low wellbeing did not live in families with no parents employed. Children in single parent families and in stepfamilies comprised $12.5 \%$ and $6.6 \%$ of the study population, respectively. An odds ratio of about 1.5 combined with the magnitude of these groups means that family type contributed more to the distribution of ill health and wellbeing among children in the Nordic countries than did parents' labour market participation.

\section{Study strengths and weaknesses}

Information on children's health and wellbeing can be derived from a variety of sources. In this study, the mailed questionnaire instructed the parent who was most familiar with the child's situation to fill in the questionnaire together with the child and the other parent if possible.

The samples were representative in each country, and a broad age range was chosen. A response rate of $67.6 \%$, corresponding to 10317 participating children was obtained.

Did non-response bias the results? Respondents and non-respondents were compared in Denmark and Norway. In 


\section{Key points}

- Children living in families with no parents employed are in increased risk for negative health outcomes.

- Associations between parents' labour market participation and children's health and wellbeing are found in all five Nordic countries.

- Social class, family type, and parents' immigrant status are important confounding variables. However, these variables do not explain the associations between parental employment status and children's health and wellbeing

Finland and Sweden non-respondents were assessed using data from the national registers for children. (Non-response analysis was not performed in Iceland.) These analyses showed that non-response was higher among parents not in paid work, parents with little or no education, parents from ethnic minorities, and single parents. This would probably tend to underestimate the associations described here. However, the decisive factor is whether non-response varies among participating and non-participating parents depending on the health and wellbeing of their children. Even though there might be such an association, there is no reason to expect it to be strong. By contrast, the more disadvantaged people in each group would be expected to be overrepresented among non-respondents.

The parents reported the data. However, the parents were instructed to fill in the questionnaire together with the child, and almost half the children aged 7 to 17 years were reported to have participated in completing the questionnaire. Parent reported data were chosen mainly to cover the wide age range of children and to obtain reliable data on items concerning the parents. As children differ in their tendency to report symptoms to their parents, there was probably some underreporting. The parents' reports on their children can depend on their own health and wellbeing; parents with health problems would be expected to report more health problems among children than would parents without health problems. This might be a problem because symptoms and diseases are not equally distributed among parents outside compared with in the labour market. These problems are very complex, however, since psychosomatic symptoms as a reaction to stress have some element of learning incorporated..$^{40-43}$

The gender of the respondent was associated with the prevalence rates of all three indicators of health and wellbeing. Respondent was included in the analysis as confounder.

Parents' labour market participation was dichotomised: at least one parent in the family employed within the past six months compared with none employed. Thus, the selected families made up a group with a very weak connection to the labour market at the time of the investigation. A continuum exists between being fully integrated at the labour market and being ostracised from the labour market. Furthermore, the causes for parents not to be employed are many and the differentiation of being intentionally or forced unemployed are often obscure. By selecting families with no parents employed currently or any period during the past six months a more homogeneous group was selected with minimal proportion of parents who have chosen that situation. Parents in an educational programme comprise a problem, as this group includes, for example, teenage single mothers in primary school, parents in social rehabilitation programmes, and parents with one young child finishing their university education. Of the single parents not in paid work, 34\% were in an educational programme. Their children did worse than or the same as other children with no parent in paid work on the three indicators. It seems rational to include single parents in an educational programme in the group not in paid work.
Children in two parent families with both parents in an educational programme comprise $15 \%$ of the children in two parent families with no parent in paid work. Children in these families were comparable to other children in health and wellbeing. Because this group was small, these families are combined with the other families with no parent in paid work. This only diminutively weakens the found associations between parents' labour market participation and children's health and wellbeing.

Three indicators were used to measure health and wellbeing among children: recurrent psychosomatic symptoms, chronic diseases, and low wellbeing. The most frequent symptoms were abdominal pain and headache. Several studies investigating the causes of abdominal pain among children have shown that the symptoms have psychosocial origin in $95 \%$ of cases ${ }^{44-47}$ For headache, about $75 \%$ of cases have a psychosocial pathogenesis. ${ }^{48}$ To some degree, the same can be assumed to be the case for the other symptoms reported in this study. Therefore the measure for recurrent psychosomatic symptoms reflected the burden of these symptoms in the child.

Chronic disease in this study covered one or more specific diseases, disorders, defects, impairments, or disabilities that had considerably affected the child's daily life during at least three months of the previous year. The most frequently reported diseases were asthma, allergies, and eczema, all atopic conditions with a multifactorial pathogenesis. Advantaged socioeconomic groups have higher prevalence rates of hayfever and childhood eczema but not asthma. ${ }^{40}$ Despite these results from other studies we found an increased burden of chronic diseases among children in families with no parents in paid work by combining all chronic diseases.

The measure for wellbeing was an index constructed and validated by Lindström as part of a measure of the quality of life of children in the Nordic countries. ${ }^{32}$ The purpose was to evaluate a proxy for the child's self esteem. As the parents reported the data, the self esteem of the parent can interfere with their response to these items. This can be regarded as a weakness in studies with parent reported data. Conversely, parents' self esteem may be a part of the pathway between parental unemployment and ill health and wellbeing among their children.

The age and gender of the child, the respondent parent, family social class, the family type, parents' immigrant status, and the country are included as confounders in all analyses. These variables are all statistically significant associated with health and wellbeing among children in this study. Including these confounders have strengthened the found associations between parents' labour market participation and children's health and wellbeing.

\section{Mechanisms}

Our study shows that parents' labour market participation was associated with health outcome among children, but the odds ratios were modest. Also social class, family type, and parents' immigrant status were associated with health indicators. All these variables are included in an extensive range of risk factors and protective factors acting together. Each of these factors on its own may contribute only modestly to the social gradient in health. However, the social structure leads to clustering of advantages and disadvantages at any particular time in a person's life and throughout the life course. ${ }^{251}{ }^{52}$ Risk factors can be social, economic, or biological status, behaviour or environments that are associated with or cause increased susceptibility to a specific disease, ill health, or injury. In this study clustering of risk factors were also shown in that families with no parents employed more often were single parent or step-parent families, immigrant families and/or from lower social classes. However, several studies show that it is not possible to predict about the life trajectory of an individual child or adolescent based on these associations between risk factors and health indicators. 
The direction of causes cannot be revealed thoroughly in this cross sectional study, but it is not likely to ascribe parents' labour market participation to the health of their children, in that the associations were found in all age groups and for psychosomatic symptoms as well as for chronic illness. The mechanisms behind the shown associations are not known but they are various: mental strain put on the family and thereby on the child, financial strain, and maybe increased level of risk behaviour, for example, smoking behaviour, contact with the health care system, etc. Also, how do we explain the marked individual variation in children's response to stress and adversity? Some succumb and some escape harm. The concept of resilience has been introduced to explain the complicated mechanisms involved. ${ }^{53}$ Resilience is concerned with individual variation in response to risk. However, resilience is not a fixed attribute of the person. If circumstances change, resilience alters. Resilience results in part from the balance between protective mechanisms and vulnerability. Vulnerability and protective mechanisms are the negative and positive poles of the same concept, the essence being that vulnerability or protective mechanisms are evident only in combination with the risk variable. Protective factors include both individual and environmental characteristics that ameliorate a person's response to constitutional risk factors or stressful life events. ${ }^{54}$

\section{Conclusion}

Children in families marginalised by the labour market had higher prevalence of ill health and low wellbeing. These associations were found in five Nordic countries despite differences in employment rates and social benefits.

\section{Authors' affiliations}

C Reinhardt Pedersen, M Madsen, National Institute of Public Health, Copenhagen, Denmark

\section{REFERENCES}

Kumar V. Poverty and inequality in the UK: the effects on children. London: National Children's Bureau, 1993.

2 Spencer N. Poverty and child health. Oxford: Radcliffe Medical Press, 1999.

3 Susser MW, Watson W, Hopper K. Sociology in medicine. New York: Oxford University Press, 1985

4 Wise P, Meyers A. Poverty and child health. Paediatr Clin North Am 1988:35: $1169-86$

5 Olsen O, Madsen M. Effects of maternal education on infant mortality and stillbirths in Denmark. Scand J Public Health 1999;2:128-36.

6 Köhler L. Infant mortality-the Swedish experience. Annu Rev Public Health 1991;12:177-193.

7 Carstairs V, Morris R. Deprivation and health in Scotland. Aberdeen: Aberdeen University Press, 1992

8 Ericson A, Eriksson M, Westerholm P, et al. Pregnancy outcome and social indicators in Sweden. Acta Paediatr Scand 1984;73:69-74.

9 Madge N. Unemployment and its effects on children. J Child Psychol Psychiatry 1983:24:311-19.

10 Garfinkel BD, Froese A, Hood J. Suicide attempts in children and adolescents. Am J Psychiatry 1982;139:1257-61.

11 Schwefel D and the Group of consultant experts on the effect of long-term unemployment on health. Unemployment, health and health services: results of German unemployment research. Strasbourg: Council of Europe, 1984

12 Maclure A, Stewart GT. Admission to hospitals in Glasgow. Relation to unemployment and other deprivation variables. Lancet 1984; ii:682-5.

13 Christoffersen MN. A follow-up study of long-term effects of unemployment on children: loss of self-esteem and self-destructive behaviour among adolescents. Childhood 1994;4:213-20.

14 Madsen M, Lindahl A, Osler M, et al. Børns sundhed ved skolestart 1988/1989 [Children's health upon entering school in Denmark, 1988/1989]. Copenhagen: National Institute of Public Health, 1991.

15 Rasmussen M, Due P, Holstein BE. Skolebørnsundersøgelsen 1998 [Survey of schoolchildren's health in Denmark]. Copenhagen: Danish Committee for Health Education, 2000.

16 West P. Health inequalities in the early years: is there equalisation in youth? Soc Sci Med 1997;44:833-58.

17 Rakkonen O, Lahelma E. Gender, social class and illness among young people. Soc Sci Med 1992;35:649-56.

18 Currie CE, Elton RA, Todd J, et al. Indicators of socio-economic status for adolescents: the WHO Health Behaviour in School-aged Children Survey. Health Educ Res 1997;12:385-97.
19 Van der Lucht F, Groothoff JW, Koopmans PC, et al. Socio-economic health differences among children aged 10-11 in the Netherlands. Eur J Public Health 1992;2:24-8.

20 Jones L. Unemployment and child abuse. Fam Soc J Contemporary Hum Services 1990;71:579-88.

21 Baum A, Fleming R, Reddy DM. Unemployment stress: loss of control, reactance and learned helplessness. Soc Sci Med 1986;5:509-16.

22 Ensminger ME, Celentano DD. Unemployment and psychiatric distress: social resources and coping. Soc Sci Med 1988;27:239-47.

23 Jahoda M. Employment and unemployment: a social psychological analysis. Cambridge: Cambridge University Press, 1982.

24 Duncan GJ, Brooks-Gunn J, Klebanov PK. Economic deprivation and early childhood development. Child Dev 1994;65:296-318.

25 Harris PL. The child's understanding of emotion: developmental change and the family environment. J Child Psychol Psychiatry 1994;35:3-28.

26 Esping-Andersen G. Three worlds of welfare capitalism. Cambridge: Polity Press, 1990

27 Nordic Social-Statistical Committee. Social protection in the Nordic countries 1997. Copenhagen: Nordic Social-Statistical Committee, 1999.

28 Hansen EJ. En generation blev voksen: den første velfærdsgeneration [A generation of adolescents growing up: the first welfare generation]. Copenhagen: National Institute of Social Research, 1995 (Report 95:8)

29 Halldórsson M, Cavelaars A, Kunst A, et al. Socio-economic inequalities in health and well-being of children and adolescents in Iceland. Scand J Public Health 1999;27:43-7

30 Berntsson L. Health and well-being of children in the five Nordic countries in 1984 and 1996. Göteborg: Nordic School of Public Health, 2000.

31 Köhler L. Barn och barnfamiljer i Norden. En studie av välfärd [Children and families with children in the Nordic countries. A study of welfare]. Göteborg: Nordic School of Public Health, 1990.

32 Lindström B. The essence of existence. On the quality of life of children in the Nordic countries. Göteborg: Nordic School of Public Health, 1994.

33 Statistics Sweden. Socio-economic classification - (SEI). Stockholm Statistics Sweden, 1982.

34 Altvén G. The covariation of common psychosomatic symptoms among children from socio-economically differing residential areas. An epidemiological study. Acta Paediatr 1993;82:484-7.

35 Dunn J, Deater-Deckark K, Pickering K, et al. Children's adjustment and prosocial behaviour in step-, single-parent, and non-stepfamily settings: findings from a community study. ALSPAC Study Team. Avon Longitudinal Study of Pregnancy and Childhood. J Child Psychol Psychiatry 1998;39:1083-95.

36 O'Connor TG, Davies L, Dunn J, et al. Distribution of accidents, injuries and illnesses by family type. ALSPAC Study Team. Avon Longitudinal Study of Pregnancy and Childhood. [Abstract.] Paediatrics 2000;106:E68

37 Schaffer HR. Making decisions about children. 2nd edn. Oxford: Blackwell, 1998.

38 Dunn J. Stepfamilies and children's adjustment. Arch Dis Child 1995;73:187-9.

39 Rajmil L, Fernandez E, Gispert R, et al. Influence of proxy respondents in children's health interview surveys. J Epidemiol Community Health 1999:53:38-42.

40 Osborn RB, Hatcher JW, Richtsmeier AH. The role of social modelling in unexplained pediatric pain. J Pediatr Psychol 1989;14:43-61

41 Wood BL. Beyond the "psychosomatic family": a biobehavioral family model of paediatric illness. Fam Process 1993;32:261-78.

42 Goodman JE, McGraft PJ. The epidemiology of pain in children and adolescents: a review. Pain 1991;46:247-64

43 Bowlby J. Attachment and loss. London: Hogarth Press and the Institute of Psycho-analysis, 1982.

44 Apley J. The child with abdominal pains. Oxford: Blackwell, 1975.

45 Jonsell R. [Clients at a paediatric outpatient clinic] [Dissertation.] Umeå, Sweden: Umeå University, 1974:11.

46 Stickler GB, Murphy DB. Recurrent abdominal pains. Am J Dis Child 1979:133:486-9.

47 Burry RG. A study of 111 children with recurrent abdominal pains. Aust Paediatr J 1987;23:1 17-19.

48 Altvén G. Psychosomatic tension headaches among children-a survey Läkertidningen 1986;45:3827-8.

49 Williams HC, Strachan DP, Hay RJ. Childhood eczema: disease of the advantaged. BM 1994;308:1132-5.

50 Lewis SA, Dritton JR. consistent effects of high socioeconomic status and low birth order, and the modifying effect of maternal smoking on the risk of allergic disease during childhood. Respir Med 1998;92:1237-44.

51 Davey Smith G, Blane D, Bartley M. Explanations of socio-economic differences in mortality: evidence from Britain and elsewhere. Eur J Public Health 1994:4:131-44.

52 Kuh D, Ben-Shlomo Y. A life-course approach to chronic disease epidemiology. Oxford: Oxford University Press, 1997.

53 Rutter M. Psychosocial resilience and protective mechanisms. Am J Orthopsychiatry 1987:57:316-31.

54 Werner EE. Protective factors and individual resilience. In: Meisels SJ, Shonkoff JP, ed. Handbook of early childhood intervention. Cambridge: Cambridge University Press, 1990. 